\title{
Pharmacy: Looking Back to See the Future
}

\author{
In preparing for further change in the pharmacy profession, \\ pharmacists must understand where we have been and look \\ for ways to shape, not simply survive, the future.
}

\section{Warren Richards}

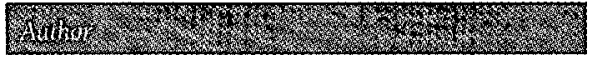

WARREN RICHARDS, PH.D., is Assistant Professor of Pharmacy Administration, College of Pharmacy and Health Sciences, Butler University, Indianapolis, IN.

Copyright(c) 1998, Academy of Managed Care Pharmacy, Inc. All rights reserved.
$\mathrm{M}$ any simultaneous events within and outside the practice of pharmacy are shaping the future for pharmacists. As we face this uncertain future, a brief look back may help us reflect on where we have been, while offering insight into where we are going, or should go. Pharmacy is an inextricable part of the health care delivery system and will be influenced byand hopefully will influence - events occurring within the health care system as a whole.

\section{CONCERN ABOUT COSTS}

Health care once again is a hot topic, as it was during the 1992 political season. Any doubts then that health care would become a political football were erased when Harris Wofford, a vocal proponent of universal health care, won his Pennsylvania senate race. 'ThenPresident George Bush advocated a market-oriented plan to increase insurance coverage to more Americans, but his Democratic opponents pushed "play or pay" as their choice. ${ }^{2}$ Most candidates favored changing the system, but their suggestions for how to reform and how to pay for that reform were characteristically vague. Candidates Bush and Bill Clinton agreed that uninsured Americans should have some coverage, but Clinton discussed universal health coverage as a right, not a privilege. Once elected, President Clinton began to attack the pharmaceutical industry and entertained suggestions both to reduce tax credits for operations in Puerto Rico and to implement outright price controls as part of his effort to get tough with health care delivery systems. ${ }^{3}$

The media concentrated on the costs involved with the delivery of health care. Time magazine featured an article that warned of health care's "Condition Critical," which reported that the American economy devoted approximately $13 \%$ of Gross National Product to health care-a figure that continued to grow each year. ${ }^{4}$ The Commerce Department predicted that health care expenditures would grow by $12 \%-13 \%$ annually, reaching $\$ 1$ trillion by 1995 , if nothing was changed. Consumer Reports revealed that between 1980 and 1990 general inflation rose $58 \%$, overall health costs climbed $117 \%$, and drug costs increased $152 \%$, making prescription drugs the largest out-of-pocket medical expense for $75 \%$ of citizens older than $65 .^{5}$ America may be mortgaging its future by increasing health care expenditures at the expense of education, housing, and the infrastructure

The debate on controlling health care costs is not new, but the impetus for change has accelerated recently as consumers and health care payors increasingly question expenditure decisions. The cost of care for the indigent is of particular concern, fueling the discussion about how we can meet competing health care wants with limited resources

Any changes that are made, however, must be socially acceptable. This was not the case with the Medicare Catastrophic Coverage Act of 1988, which was debated, passed, and then 
repealed in a little over 30 months, largely because of opposition to its financing methods by those who were intended to benefit under the law. Although universal coverage-especially under a government umbrella-now is largely out of favor, the debate rages on.

Business, too, is concerned about the cost of health care, which represents a significant portion of the benefits corporations pay to and for employees. In 1992, Medical Economics Publishing created two special reports on Business $\&$ Health, funded by Marion Merrell Dow and directed toward the health benefits community, that addressed pharmaceuticals and the role of prescription drugs in health care today. ${ }^{6}$ In the report, "The Value of Pharmaceuticals," it was correctly pointed out that payors expect drug therapy to improve patient outcomes and be cost effective; however, it cautioned that cost effectiveness should not be confused with cost containment. The publication also addressed the issue of patient compliance, drug utilization review (DUR), and the pharmacist's role in controlling costs. Other articles touted the benefits of biomedical technology, over-the-counter drugs, and research into new drug entities, especially for the aging population.

The second report, "Managed Care Comes to Prescription Drugs," "7 warned that efforts directed solely at cost containment may adversely affect quality of care. The benefits of DUR in controlling drug therapy were addressed in a related article, which suggested that one important role for DUR is the reduction of iatrogenic disease, which is responsible for approximately $7 \%$ of all hospitalizations. The report indicated that iatrogenic diseases are caused in part by inappropriate prescribing in $25 \%-30 \%$ of the general population and in $40 \%$ of those over $65 .{ }^{8}$

The cost of health care is also an important issue for the growing elderly population in America. In Modern Maturity, the magazine of the American Association of Retired Persons, Rashi Fein ${ }^{9}$ of Harvard University described the breakdown of who pays for health care and who receives payments. Fein further discussed the pros and cons of private-market, employer-based, and government-based approaches to health care reform. The article also contained a questionnaire to measure the readership's attitudes about various aspects of health care. Because the elderly consume a disproportionate amount of health care and spend a disproportionate amount of their resources on health care, the concerns shared by and about the elderly are indeed relevant to any examination of health care delivery.

The debate over which payment system is best will continue. Traditional insurance continues to be the choice of many policy makers. Managed care has helped insurance companies control the rate of premium increases to the point that the rate of increase declined in 1990 for the first time since $1987 . .^{10}$ Others, however, believe that traditional health insurance no longer serves widely shared social objectives and should be scrapped as reform reshapes the payment schemes for health care delivery.

The Canadian health care system has received much attention in the context of our own national debate. Some question whether drug benefits should even be part of a nationalized health care plan. Christensen ${ }^{1 t}$ argued in a 1980 article that prescription benefits should be included in health care coverage because of their important role in mitigating morbidity and mortality and their cost effectiveness. He argued that patient-centered drug therapy represents an important opportunity to improve the health status of Americans.

The goal of pharmaceutical care is to provide optimal drug therapy and alleviate drug usage problems in society. Manasse ${ }^{12}$ warned of the dangers of "drug misadventuring" leading to an iatrogenic incident exacerbated by "polypharmacy" (one patient with multiple conditions taking many medications). Gans ${ }^{13}$ told the President's Task Force on National Health Care Reform that empowering pharmacists will
Figure 1. Reasons for Increasing Health Care Costs

Aging of the population

A Physician surplus

A Nurse shortage

$\boldsymbol{\Delta}$ Increased use of technology

- The fallacy of health insurance

A Epidemiologic vagaries such as AIDS

A The malpractice problem

A Presence of uninsured and underinsured patients

improve the quality of drug use. Many pharmacists will find their new roles and responsibilities to be exhilarating or frightening, or both. For those daunted by the tasks ahead, the advice is to start small and document as you go.

Rupp ${ }^{14}$ found that pharmacists' interventions can prevent potential harm to the patient and save the health care system real dollars. His work demonstrated that these interventions offered in a patient-centered practice add value to the health care system- $\$ 2.32$ per prescription screened in this study. ${ }^{15}$ The Omnibus Budget Reconciliation Act of 1990 (OBRA 90) recognizes that phar-" macy services add value beyond the pharmaceutical product. Proper documentation of pharmacists' interventions provides tangible evidence of the influence of pharmacy services on patient outcomes. In light of current budgetary constraints, however, compensation for these value-added services still seems unlikely.

\section{THE HEALTH CARE DILEMMA}

According to William Roper, ${ }^{16}$. former administrator of the Health Care Financing Administration, many Americans believe that major problems exist within our health care delivery system. Modest, incremental changes in the system no longer are acceptable. Many critics of the system have advocated a major overhaul with fundamental reforms. The 


\section{Continued from page 455}

question seems not to center on whether to reform, but rather how to reform.

The overriding concern appears to be the cost of health care. Spending on health services and supplies rose $10 \%$ in 1990 over 1989, the third consecutive year for a double-digit increase. ${ }^{17}$ Hughes $^{18}$ enumerated reasons for increased costs (see Figure 1). Increases in pharmaceutical costs compared to total health care costs ranged from $3 \%-4 \%$ to $10 \%-12 \%$ for some managed health plans. ${ }^{7}$ But according to Roper, "Our health system has plenty of money; we are just not spending it wisely."

Another concern is uneven access to health care. The Medicare and Medicaid programs were enacted to open access to health care for citizens who had been excluded by their inability to pay. Budget constraints have limited the success of these programs. Rationing has been discussed. Managed care programs have been established to control costs that limit access.

The quality of care received also is a major concern. Care must be clinically appropriate as well as of high quality. $\mathrm{A}$ high-quality surgical procedure is not high-quality medical care if the procedure was not clinically appropriate. The effectiveness of medical care must be researched to better examine quality-ofcare issues.

\section{THE EVOLUTION OF PHARMACY}

The practice of pharmacy is evolving even as the health care delivery system is coming under attack. Some practitioners are uncomfortable with the rapid rate of change in pharmacy resulting from social and economic mandates in cost control, self care, home care, longterm care, and biotechnology.

It takes a pioneer spirit to challenge the forces that resist change in pharmacists' roles. The move from a productcentered to a cognitive services-centered practice for pharmacy has been described as a "midlife crisis." Practicing pharmacists are struggling with dilemmas like the Pharm.D. sole-entry degree issue,
DUR, case management, chronic disease monitoring, managed care, and the proper utilization of technicians. The profession will have to accept new ways of doing things. Advances in technology will make pharmacy a much different profession in the future.

Change is occurring at a rapid rate. The total body of information doubles every 22 months. ${ }^{19}$ Admitting that we fear change is the first step in dealing with change. With that out of the way, we can focus our energies on creating a new vision for pharmacy practice and move into the future with confidence. Dobis $^{20}$ stressed that not only is pharmacy changing, but also that pharmacy must change, and he cautioned his fellow pharmacists to become aware of the many changes around them.

New roles for pharmacists will involve solving health care problems rather than selling drugs. Patient-centered clinical services should be offered to all patients, reflecting the highest practice standard attainable. The patient's health-related quality of life has become an issue. Pharmacists will be expected to interact with the patient as a whole person who exists in the real world and not simply dispense a drug

Pharmacists' effectiveness and the quality of their efforts will be closely monitored and measured, using indicators focused on treatment outcomes. Performance indicators will act as screening mechanisms to monitor and evaluate quality and effectiveness. Quality in pharmaceutical services is particularly important for the elderly patient who, because of the use of multiple drugs, is especially vulnerable to adverse consequences of therapy.

Former Food and Drug Administration Commissioner Dr. David Kessler sees pharmacists as members of a health care team disseminating information to patients to prevent adverse consequences. ${ }^{21}$ Pharmacists also should provide this information for physicians who are not schooled in the nuances of drug actions. Pharmacy must harness technological advances to take advantage of the "infor- mation revolution" as it moves into the future. Knapp ${ }^{22}$ discussed trends that will shape the practice of pharmacy in the coming years (see Figure 2). The nature of pharmacy practice in the future will depend on unfolding events and the efforts of pharmacy to shape or precipitate these critical events.

Coster $^{23}$ suggested that the enactment of OBRA 90 was a watershed event for pharmacy because Congress went on record supporting the clinical role of pharmacists. Enacted to save taxpayer dollars, the law also mandated DUR and patient counseling for Medicaid patients. The American Pharmaceutical Association has stated that pharmacy is now at a crossroads, with two possible future scenarios: continuation of the current narrow distributive role, or expansion to a new cognitive services role, with the current, less-attractive role most likely. ${ }^{27}$ Various pharmacy organizations have tried to persuade health care policy makers that pharmacists' interventions can reverse suboptimal drug use and save the system tax dollars. Considering current health care reform efforts, there may be some hope for a productive future for patient-centered pharmacists, but there also is considerable doubt.

Whatever pharmacy evolves into, it will face greater involvement with managed care in the future. Direct coverage of prescription drugs by third-party plans more than doubled from 1969 to 1986 and was expected to double again by $1995 .{ }^{25}$ In addition to controlling costs, managed care systems seek a posi-

Figure 2: Trends Shaping Future Pharmacy Practice

A Cultural diversity

A Aging population

A Drug technology

A Information science

A Ever-more-expensive drugs

A Organization and financing of drugs and pharmaceutical care 
tive effect on the patient's health care status and improvement in the patient's quality of life. By cooperating in the design and implementation of a patient therapy plan to produce specific, optimal outcomes and by monitoring the patient's response to drug therapy, pharmacists participate directly in managing patient care. For most community pharmacists, this is a significant change.

The defining phrase for change in pharmacy today probably is "pharmaceutical care." Hepler and Strand ${ }^{26}$ described the opportunities and the responsibilities associated with a move to pharmaceutical care as a method of pharmacy practice. Pharmaceutical care requires pharmacists to view the patient from the broad biopsychosocial perspective. By applying the tenets of clinical pharmacy, the pharmacist can address drug-related morbidity and mortality. Because the problem often lies less with the drug than with its utilization, a cooperative effort with other professionals is critical to solving drug-induced untoward effects. The question remaining for Hepler and Strand is whether pharmacists possess the skills and knowledge to accomplish these goals.

Hepler believes pharmaceutical care is pharmacy's future as health care evolves and pharmacy matures. ${ }^{27}$ Pharmaceutical care remains a new concept for many pharmacists, who need time to understand and come to terms with its demands. Pharmacists will have to learn new ways to document their activities, a basic requirement in providing pharmaceutical care. Pharmacists will be expected to monitor patient outcomes, which means they will need more information about the patient than is available to them under the current system. The pharmacist will function as a manager of patient therapy with the responsibility to ensure positive impact on patient outcomes. Because pharmaceutical care encompasses a wide scope of activities, a plan must be developed to assess and resolve therapy problems. This reinforces the need for pharmacists to document their activities.

Pharmaceutical care is becoming the accepted norm for pharmacy practice and has been integrated into mission statements for many organizations within pharmacy. It is seen as the embodiment of a longer-term vision for the practice of pharmacy. There are barriers to the implementation of pharmaceutical care within and outside the profession of pharmacy, including the issue of whether current practitioners are competent to pursue this new practice. The patient-centered paradigm combines the traditional distributive role of the pharmacist with new clinical obligations and responsibilities toward the patient. The pharmacist and patient are no longer passive in the process of health care delivery. Their partnership is based on independent, voluntary consent to work toward mutually agreed-upon outcomes that maximize therapeutic value for the patient.

America's pharmacists must retool. With the advent of managed care, self care, home care, and profile monitoring, patients are seeking more information from the pharmacist. OBRA 90 mandated patient counseling, which requires the sharing of information not previously present in the patient-pharmacist dialogue. Pharmaceutical care now is seen, at least by some, as the concept on which a pharmacist's professional responsibilities are based. Comprehensiveness of disclosures to patients, patient confidentiality, and drug product selection are among the ethical dilemmas pharmacists will face.

One characteristic of a professional is an emotional-as well as intellectualcommitment to ethics. This new pharmacy ethic suggests a patient-centered paradigm in which the pharmacist becomes an advocate for the patient to promote autonomy and prevent harm. The new paradigm may place pharmacists in patient's homes, schools, or the offices of other health professionals as clinical services establish pharmaceutical care as a necessary element of health care. The question remains whether pharmacists have sufficient training to fulfill some of these new practice demands.

The concept of pharmaceutical care appears to be here to stay. The eighth annual Imperial Chemical Industries Pharmaceutical Group symposium for Pharmacy Association Executives in 1991 devoted its entire schedule to addressing the opportunities, challenges, and changes ahead under pharmaceutical care. The following year, at their ninth annual conference, this group tackled how to make pharmaceutical care work. Pharmacy organizations should follow mission statements that incorporate pharmaceutical care with practice goals for their members. The Indiana Pharmacy Consensus-Building Conference of 1991 found that, "Among pharmacy practitioners, there is lack of a universally adopted standard of practice derived from a consensus on the mission of pharmacy practice. ${ }^{\prime 28} \mathrm{~A}$ majority of practitioners was said to be unaware of the scope and goals of pharmaceutical care. Dobis ${ }^{29}$ warned Indiana pharmacists to wake up, that "...the future of pharmacy begins today."

The road of change to pharmaceutical care will not be without difficulties. Standards of practice are expected to be as dynamic as the new practice of pharmacy itself. Pharmacy's code of ethics has been attacked as outdated. New legal liabilities may appear. Pharmacists will have to learn to document their interventions as they monitor patients' drug therapy. Departments and professionals must cooperate and coordinate in the exchange of information in order to deliver optimal patient care. New technologies must be mastered.

\section{A LOOK AHEAD}

Pharmacy has changed and continues to change even as health care delivery systems change around us. As the future unfolds, pharmacy must find ways to improve continuity of care for patients as they are admitted to and discharged from acute care settings. Many are advocating integrated health care delivery systems (IDSs) that involve a wide range of providers as a way to achieve a seamless system of patient care. 
Continued from page 460

An IDS, comprising physicians, hospitals, other health care providers, and insurers then would negotiate with managed care organizations to provide patient care for their clients. The fact that in $199485 \%$ of hospitals reported some type of arrangement with preferred provider organizations indicates that this process is currently widespread.

A growing number of agreements between providers and payors involves innovative compensation schemes, such as a capitated system in which providers share financial risk with payors. While this type of system may directly address cost-of-care issues, it does nothing to ensure quality of care. Because of the complexities of these alternate payment systems, pharmacists should become familiar with capitation programs and participate only after careful study. The risks are real.

Others, taking a more global perspective over the long view, believe it is essential that an integrated health care system also address wellness issues, contending that wellness, fitness, and prevention of disease in a healthy population are as important as high-quality, cost-effective interventions for illness and injury. Such a system would seek health care value over the patient's life.

There are barriers to the establishment of such a system in our current health care delivery environment. Fortunately, knowledge is not one of them. Individual practitioners have access to increasingly comprehensive and specialized medical and pharmaceutical knowledge. The difficulty is leveraging that individual knowledge into a patient care system. Pharmacists in the future will be working with information systems and applying outcomes research in their roles as information manager, teacher, and consultant. Clearly, pharmacists will be managing technologies and personnel and will be compensated for their cognitive abilities.

Will these projections come true? Obviously, it is difficult to predict what the future may hold, although we can be assured it will hold more change. The challenge for pharmacists and pharmacy is to not only be ready for change, but also to work within existing frameworks to influence our future. Knowing where we are and how we got here should help us identify and avoid practice-limiting events as we help shape our own future.

\section{$\Delta \quad$ References}

1. Laskoski G. The great health debate of 1992. Am Druggist 1992(Jan); 205(2): 26-32.

2. Schwartz RM. Health care: round one. Am Druggist 1992(Mar); 205(3): 9-14.

3. Schwartz RM. Clinton marches in. Am Druggist 1992(Dec); 207(1): 9-10.

4. Castro J. Condition critical. Time 1991(Nov); 138(21): $34-42$.

5. Anonymous. Pushing drugs to doctors. Consumer Reports 1992(Feb); 57(2): 87-94. 6. Siegelman S. An "expensive" drug may be the most cost effective. Business \& Health, Special report: the value of pharmaceuticals. Montvale, NJ: Med Economics Publishing, 1992: 8-14.

7. Epstein D. Putting the squeeze on drug benefit costs. Business \& Health, Special report: managed care comes to prescription drugs. Montvale, NJ: Med Economics Publishing, 1992: 6-11.

8. Epstein D. Drug utilization: the ultimate strategy. Business \& Health, Special report: managed care comes to prescription drugs. Montvale, $\mathrm{NJ}$ : Med Economics Publishing, 1992: 19-23.

9. Fein R. Prescription for change. Modern Maturity 1992(Sep); 35(4): 23-35.

10. Sullivan $C B$, Rice $T$. The health insurance picture in 1990. Health Affairs 1991(Summer); 104-15.
11. Christensen DB. Guiding principles of pharmacy services under national health insurance. Pharm Management 1.980(Sep-Oct); 152 (5): 205-09. 12. Manasse HR: Medication use in an imperfect world: 'misadventuring as an issue of public policy, part 1. Am J Hosp Pharm 1989; 46: 929-44.

13. Martin S. APhA voices pharmacists' concerns. Am Pharm 1993(May); NS33: 25-27.

14. Rupp MT. Evaluation of prescribing errors and pharmacist interventions in community practice: an estimate of "value added." Am Pharm 1988(Dec); NS28: 22-26.

15. Rupp MT. Value of community pharmacists' interventions to correct prescribing errors. Ann Pharmacotherapy 1992; 26: 1580-84.

16. Roper WL. Financing health care: a view from the White House. Health Affairs 1989(Winter); 97-102.

17. Anonymous. News briefs from research, industry, and the medical literature. Pharm Today 1992(March); 3l.(6): 3.

18. Hughes EFX. Trends in health care systems delivery. Am J Pharm Ed 1989(Winter supplement); 53: 49S-54S.

19. Schwartz MA. On fear, vision, and power. Am J Hosp Pharm 1992; 49: 1401.

20. Dobis CG. Another perspective on change.

Indiana Pharmacist 1992(May); 4-5.

21. Rubin I. FDA chief answers 10 questions on RPhs' expanding health role. Welcome Trends Pharm 1992(May); 45(3): 3-7.

22. Knapp DA. Pharmacy practice in 2040 . Am J Hosp Pharm 1992; 49: 2457-61.

23. Coster JM. A watershed event for pharmacy practice. US Pharmacist 1991(Jan); 16(1): 56-61. 24. Anonymous. A year of decision in health care reform. Am Pharm Assoc, Washington, DC, Jan 1993; 1-10.

25. Schondelmeyer SW. Impact of third party and managed care programs on pharmacy practice. Welcome Trends Pharm 1988(Nov); 2-10. 26. Hepler CD, Strand LM. Opportunities and responsibilities in pharmaceutical care. Am J Pharm Ed 1989(Winter supplement); 53: 7S-15S. 27. Hepler CD. The future of pharmacy: pharmaceutical care. Am Pharm 1990(Oct); NS30: 23-29 28. Anonymous. A strategic planning initiative for Indiana pharmacy in the ' 90 s. Proceedings from the Indiana Pharmacy Consensus-Building Conference, 1991.

29. Dobis CG. Button messagés. Indiana Pharmacist 1992(Aug); 73(8): 4-5. 